\title{
Europeização ou erosão das relações laborais?
}

The Europeanization - or the Erosion - of Industrial Relations?

Européanisation ou érosion des relations au travail ?

\section{Richard Hyman}

Tradutor: João Paulo Moreira

\section{(2) OpenEdition}

\section{Journals}

\section{Edição electrónica}

URL: http://journals.openedition.org/rccs/1296

DOI: $10.4000 /$ rccs. 1296

ISSN: 2182-7435

\section{Editora}

Centro de Estudos Sociais da Universidade de Coimbra

Edição impressa

Data de publição: 1 Junho 2002

Paginação: 07-32

ISSN: 0254-1106

\section{Refêrencia eletrónica}

Richard Hyman, « Europeização ou erosão das relações laborais? », Revista Crítica de Ciências Sociais

[Online], 62 | 2002, colocado online no dia 01 outubro 2012, criado a 21 abril 2019. URL : http:// journals.openedition.org/rccs/1296; DOI : 10.4000/rccs.1296 


\section{RICHARD HYMAN}

London School of Economics

\section{Europeização ou erosão das relações laborais? ${ }^{1}$}

Este artigo reflecte sobre o impacto da integração europeia nas relações laborais. Um regime de relações laborais pode ser visto como uma tensão entre o emprego estruturado pelas dinâmicas do mercado e a regulação social mais lata, isto é, uma tensão entre os princípios do contrato e do status. A europeização económica ameaça esta relação, cuja sobrevivência poderá depender de novas formas de regulação supranacional, embora não envolva necessariamente a "dimensão social" da europeização tal como ela é usualmente entendida.

\section{Introdução}

Este texto procura relacionar uma série de temas que penso serem mais difíceis de equacionar do que geralmente se supõe, temas que são actualmente mais problemáticos a nível empírico do que quando as relações laborais foram inventadas (tanto no mundo material 'lá fora', como no mundo intelectual da análise académica). Esses temas incluem o carácter da regulação do emprego, a natureza dos mercados de trabalho e a relação entre status e contrato. A articulação entre estes temas está no centro da arquitectura dos sistemas de relações laborais e da coerência analítica desta área de estudos. Esta articulação, sempre fundamentalmente de carácter nacional, é posta em causa pela integração económica transnacional e, portanto, a europeização económica pode vir a significar a erosão, em vez da europeização, das relações laborais.

As possibilidades e perspectivas de criação de um sistema europeu supranacional de relações laborais têm vindo a ser intensamente debatidas há mais de uma década. Farei referência a alguns destes debates na parte final deste artigo. Mas penso que, antes de nos reportarmos à agenda habitual relativa à europeização das relações laborais, é essencial rever as

\footnotetext{
${ }^{1}$ Foi apresentada uma versão prévia deste artigo como conferência plenária ao congresso anual da British Universities Industrial Relations Association, que teve lugar na Universidade de Warwick em Julho de 2000.
} 
nossas concepções sobre a natureza dessas relações a nível nacional. Eu entendo-as como um campo de tensão entre a construção económica da relação de trabalho e os constrangimentos sociais mais latos ao seu carácter económico, tendo os últimos essencialmente uma especificidade nacional. Daí que o meu pressuposto seja o de que os 'mercados de trabalho' só constituem de facto mercados em aspectos limitados. Nos países da União Europeia (UE), os regimes de emprego (ou sistemas de relações laborais) representam variedades de estruturas institucionais que asseguram que a relação empregador-empregado não seja principalmente determinada pelas forças do mercado. Falar de mercados de trabalho significa adoptar - ou sugerir - uma concepção errada da natureza das relações de trabalho, concedendo implicitamente uma vantagem ideológica primordial àqueles cujo modelo ideal de uma Europa integrada é o de um mercado continental.

Portanto, formulo a questão central do seguinte modo: no contexto da integração económica europeia, qual a robustez das instituições civilizadoras que garantem que os mercados de trabalho não são verdadeiramente mercados? Podemos identificar pelo menos três tipos de pressão - derivada da intensificação da concorrência transnacional nos mercados de produtos, das decisões cada vez mais estratégicas e premeditadas das grandes empresas transnacionais e das iniciativas desreguladoras de muitos governos que, acidental ou deliberadamente, estão a fazer com que os mercados de trabalho se assemelhem mais aos mercados, fazendo pender a balança para o lado oposto do social dentro das 'economias de mercado social' na Europa. Quão radical é a viragem para as forças do mercado na determinação da relação de trabalho? Será desejável que os mercados de trabalho europeus se venham a assemelhar mais aos mercados? Ou, se as protecções institucionais contra os efeitos prejudiciais das dinâmicas irrefreadas do mercado continuarem a ser necessárias, embora a nível puramente nacional estejam a perder a sua eficácia, quais são as implicações para a intervenção regulatória a nível supranacional? Há muito tempo que Commons (1909/1968) familiarizou a tese de que as fronteiras da regulação do emprego são moldadas pela extensão dos mercados de produtos; mas este processo é tudo menos automático. Expandir os quadros regulatórios quando os mecanismos mais limitados são debilitados pela extensão dos mercados constitui um desafio e uma luta que muitas vezes enfrenta resistências. É este, obviamente, o caso de qualquer projecto relativo a um regime europeu de relações laborais. 


\section{Trabalho: a 'mercadoria fictícia'}

Será o mercado de trabalho como qualquer outro mercado? Se o é, qual é a mercadoria que é transaccionada em troca de um salário ou ordenado? Há muito que tanto economistas como advogados se têm debatido com estas questões. $\mathrm{O}$ contrato de trabalho é necessariamente aberto. Se comprarmos um quilo de batatas, estas passam a ser fisicamente nossas, enquanto o vendedor se separa delas para sempre. Mas o empregador não compra um empregado: é isto que distingue o trabalho assalariado da escravatura. Um contrato de trabalho também não especifica normalmente a quantidade de trabalho a realizar: o fluxo de tarefas de qualquer função é mais ou menos imprevisível.

Por esta razão, como Marx insistiu, o trabalho propriamente dito não é uma mercadoria: o que o/a trabalhador/a vende é a sua capacidade de trabalhar, ou seja, a sua 'força de trabalho'. Mas isto também é impreciso: nenhum contrato pode definir a quantidade de energia que será dispendida, o cuidado ou a capacidade de iniciativa que serão demonstrados. As necessidades dos empregadores raramente se podem prever ao pormenor e, portanto, estes têm vantagens em manter uma margem de manobra (geralmente ampla); por outro lado, as "descrições pormenorizadas do trabalho não são económicas” (Marsden, 1999: 15). Assim, na maioria dos casos, os trabalhadores comprometem-se, de acordo com o contrato de trabalho, a estar fisicamente presentes nas instalações do empregador durante um período de tempo que pode ou não ser especificado com precisão, bem como a aceder às exigências 'razoáveis' da gestão de acordo com critérios igualmente 'razoáveis' de diligência e eficiência.

O que a lei considera 'razoável' (ou mais frequentemente 'não razoável') tem sido em certa medida indicado pelos tribunais (evidentemente de formas diferentes nas várias instâncias jurídicas nacionais). Contudo, a autoridade juridicamente instituída do empregador tem em si própria um efeito limitado em termos práticos, pois poucas organizações empregadoras podem funcionar sem o empenhamento activo e a boa vontade da força de trabalho. Portanto, na realidade, o conteúdo do contrato de trabalho tende a ser determinado por critérios costumeiros relativos à 'jornada justa' e pelo equilíbrio da relação de dependência mútua entre empregador e empregado (ela própria afectada pelas forças variáveis da oferta e da procura no 'mercado de trabalho' externo, bem como pelas pressões dos mercados de produtos). Em condições normais, a pormenorização do que é realizado em troca de um salário ou ordenado está continuamente sujeita a uma negociação geralmente tácita. 
A negociação contínua é omnipresente ainda por outra razão: uma vez que o empregado, ao contrário do dono de batatas, não pode alienar permanentemente a sua 'mercadoria', qualquer contrato de trabalho é, em princípio, passível de ser rescindido. Mesmo um contrato 'permanente' está sujeito a um período de aviso de rescisão por parte do empregado e geralmente também do empregador. Commons coloca a questão de forma absolutamente clara: o contrato de trabalho "não é um contrato, mas uma renovação contínua e implícita de contratos a cada hora e minuto (...). Assim, o trabalhor encontra-se continuamente no mercado de trabalho - mesmo quando está a trabalhar no seu emprego, está simultaneamente a produzir e a negociar, sendo os dois inseparáveis" (1924: 285). Tomando o ponto de vista do empregador, Mitchell refere-se a uma "estratégia de renovação contingente" que subjaz à "relação empregador-empregado [como] uma forma arquetípica de troca contestada" (1998: 25-6). É evidente que, na maioria dos empregos, a opção por omissão é manter a relação existente; a 'renovação implícita' raramente se torna objecto de decisão consciente. No entanto, esta dimensão temporal é um outro factor subjacente à condição peculiar do mercado de trabalho. É de facto paradoxal que quanto mais a lógica do mercado se infiltra na relação de emprego - quanto mais cada uma das partes dá prioridade a um cálculo de custos e benefícios a curto prazo, e portanto empenha tanta energia na produção como na negociação - tanto menos esta relação se ajusta à ideia convencional das transacções de mercadorias como trocas precisas, havendo igualmente menos probabilidades de que contribua para a eficiência produtiva.

Há ainda uma outra peculiaridade da relação de emprego que merece particular atenção. O contrato de trabalho diz respeito ao trabalhador como indivíduo, mas normalmente a realização do trabalho, e portanto a relação de emprego em termos mais latos, envolve a força de trabalho como uma colectividade - o que Marx designou por 'trabalhador colectivo'. Há, portanto, uma disjunção entre a base formal da obrigação do empregado e a realidade das relações produtivas no trabalho (Erbès-Seguin, 1999: 217; Friot, 1999: 207). (Esta disjunção é evidentemente uma das razões dos efeitos frequentemente contraprodutivos das tentativas de aplicar 'remunerações por desempenho’ a nível individual.)

Por todas estas razões, o trabalho é uma 'mercadoria fictícia' (Polanyi, 1957). Contudo, num outro sentido, a relação de emprego também revela um problema mais geral que subjaz às concepções puramente económicas das relações de mercado. Segundo as conhecidas palavras de Durkheim, nem tudo num contrato é contratual: "um contrato não se basta a si próprio; ele só é possível devido a uma regulamentação do contrato que tem 
uma origem social" (1933: 211-215). Todos os sistemas de mercado estão necessariamente 'imbricados' numa estrutura de relações sociais: "o mercado anónimo dos modelos neoclássicos praticamente não existe na vida económica e (...) qualquer tipo de transacção é permeada por (...) ligações sociais" (Granovetter, 1985: 495).

Em termos empíricos, e provavelmente também lógicos, é impossível existir um mercado totalmente 'livre'. Os mercados surgiram historicamente apenas como "acessórios da vida económica. Em termos gerais, o sistema económico estava absorvido no sistema social”. Nas primeiras sociedades capitalistas, a produção e a distribuição eram firmemente reguladas por regras tradicionais e por controles estatutários específicos: "com efeito, a regulação e os mercados desenvolveram-se par a par" (Polanyi, 1957: 68). A forma que esta simbiose tomou, contudo, variou de acordo com os contextos nacionais e, em consequência, o capitalismo actual apresenta diferentes configurações nacionais com variações consideráveis no que diz respeito ao enraizamento institucional dos mercados (Crouch e Streeck, 1997).

Em parte como consequência disto, o próprio conceito de mercado é difícil de captar: "tem assumido tantos significados que o êxito de qualquer referência que se lhe faça poderá ser atribuído a definições muito vagas e parcialmente contraditórias, que inevitavelmente variam de acordo com a cultura e a língua" (Boyer, 1996: 96). Na sua análise clássica da evolução histórica do capitalismo, Polanyi faz uma tripla distinção: em praticamente todas as sociedades complexas, os mercados - a compra e venda (ou troca) de produtos, baseadas em determinadas noções padronizadas de valor têm desempenhado algum tipo de papel na vida económica. Ele define a economia de mercado, contudo, como algo muito mais específico: "um sistema económico controlado, regulado e dirigido apenas pelos mercados" (1957: 68). Dentro de uma sociedade de mercado, tal sistema económico retira legitimação ideológica do predomínio dos valores que exaltam a liberdade individual de estabelecer contratos e a busca individual do máximo proveito económico dentro de mercados competitivos. Nas famosas palavras de Marx, num tal meio ambiente o "feiticismo das mercadorias" domina as relações sociais.

Para Polanyi, a criação de uma sociedade de mercado é "totalmente não natural, no sentido estritamente empírico de excepcional" (1957: 249). O caso paradigmático é o da Grã-Bretanha do final do século XvIII e princípio do XIX, onde o estabelecimento de um regime de liberalismo económico reflectiu um esforço imenso por parte dos seus protagonistas. "Não houve nada de natural no laissez-faire; nunca poderiam ter surgido merca- 
dos livres se se tivesse deixado as coisas seguirem o seu curso. (...) O próprio laissez-faire foi imposto pelo Estado" (1957: 139). Ou, de acordo com a recente formulação de Gray, o laissez-faire "constituiu um artefacto do poder e da estadística. (...) Os mercados livres são criaturas do poder do Estado e só subsistem enquanto o Estado tiver a capacidade de evitar que as necessidades humanas de segurança e o controle do risco económico encontrem expressão política" (1998: 7, 17).

Poderá notar-se que, durante as décadas de 80 e 90, as iniciativas bastante comuns de restabelecer tais princípios com base em ideologias neoliberais envolveram esforços de alguma forma semelhantes e, portanto, é completamente errado designá-los por 'desregulação' (Standing, 1997). Tomando outra vez o exemplo britânico, a 'retirada' do Estado da regulação económica envolveu na realidade a intervenção sistemática do governo nos assuntos económicos e exigiu um aumento sem precedentes da infiltração do poder estatal na sociedade. Como o caso do Chile de Pinochet evidencia de forma ainda mais dramática, o liberalismo de mercado da escola de Chicago só podia ser imposto por uma maciça e brutal explosão do poder coercivo do Estado. Para além disto, as pressões intensificadas do mercado não têm conduzido ao estabelecimento de um regime económico impessoal, mas antes à reconfiguração do equilíbrio das forças sociais (e de classe). A 'desregulação' consagra efectivamente novas regras que intensificam a lei do valor, com efeitos que conferem poder a alguns actores económicos, ao mesmo tempo que o retiram a outros (a maioria).

Assim, apesar da ideologia neoliberal, o Estado é inevitavelmente um actor nas economias de mercado. "Longe de constituir uma interferência desnecessária, o Estado é um elemento normal dos mercados reais, uma pré-condição da sua existência. Os mercados dependem do Estado em termos de regulação, protecção dos direitos de propriedade e moeda" (Sayer, 1995: 87). Num plano diferente, como Polanyi expõe com pormenor, a regulação estatal - particularmente das relações de emprego - tem sido desenvolvida na maioria das economias de mercado como um meio de restringir o âmbito do 'livre mercado' de mão-de-obra. "Permitiu-se que o mercado de trabalho retivesse a sua principal função apenas na condição de que os salários e as condições de trabalho, os critérios e os regulamentações fossem de molde a salvaguardar o carácter humano da suposta mercadoria que é o trabalho" (1957: 177). A irrestrita liberdade de contrato entre empregadores e trabalhadores era geralmente considerada inaceitável, quer por razões humanitárias, quer por anseios relativos à potencial perturbação e desordem social que poderiam advir se a concorrência viesse a empurrar os padrões abaixo de um certo patamar. Na maioria dos sistemas capitalis- 
tas existentes, o Estado tem desempenhado um papel activo, tanto no que se refere aos estímulos ao funcionamento do mercado, como aos limites impostos à sua capacidade de moldar as condições de emprego.

Portanto, nas sociedades de mercado, a relação salário-trabalho é produto tanto de forças políticas e sociais, como de forças puramente económicas; ou melhor, o próprio contexto económico do emprego é social e politicamente estruturado. Como Thompson afirmou na sua análise do protesto social nos primórdios do capitalismo britânico, a economia política tem que ser conciliada com uma "economia moral" baseada na poderosa força das "normas e obrigações sociais" (1971: 79). Mais recentemente, "de forma a contrabalançar as desigualdades de rendimento e poder produzidas pelo mercado, os objectivos de equidade e redistribuição social têm estado no centro do contrato social que, de algum modo, tem caracterizado a maior parte dos países europeus desde a Segunda Guerra Mundial" (Regini, 2000: 12). Assim, os mercados estão sujeitos a pelo menos três tipos de determinantes potencialmente conflituais: as forças da oferta e da procura, consideradas convencionalmente pelos economistas como as únicas com significado; as políticas de intervenção dos governos, minimamente essenciais para garantir o funcionamento rotineiro das relações de mercado; e as normas sociais que influenciam os actores do mercado, muitas vezes de formas que não podem ser compreendidas em termos do simples interesse material individual.

\section{O desenvolvimento dos sistemas de relações laborais: a 'desmercadorização institucional'}

Só poderemos compreender devidamente o papel das instituições de relações laborais se tomarmos em conta a natureza do trabalho como 'mercadoria fictícia'. As relações laborais podem ser definidas como a regulação do trabalho e do emprego, desde que se entenda a regulação (controle através de regras, segundo o dicionário), no seu sentido mais lato, como abrangendo uma teia complexa de processos sociais e um terreno de resistência e luta real ou potencial.

Convém analisar as relações laborais de acordo com três conjuntos de distinções, processos sociais e estruturas de relações que podem ser complementares, mas que são muitas vezes contraditórias.

Em primeiro lugar, as relações laborais envolvem várias formas de regulação social que refractam e metamorfoseiam as dinâmicas puramente económicas da relação de emprego. Existe em todos os regimes nacionais algum tipo de interacção (embora raramente um equilíbrio) entre a regulação 'social' e a regulação 'económica'. Como já defendi, os 'mercados de tra- 
balho' não constituem mercados no sentido usual do termo, uma vez que o trabalho é uma mercadoria diferente de todas as outras e os próprios mercados 'normais' são artefactos sociais e mecanismos de poder social. Não é possível conceber um sistema produtivo que se baseie apenas numa lógica monetária - como o demonstram claramente os esforços de inventar uma economia de mercado 'pura' na Europa de Leste. Todavia, o grau em que as forças da oferta e da procura influenciam as relações de emprego varia substancialmente de acordo com o tempo e o espaço. Em termos históricos, o esforço de construir sistemas nacionais de relações laborais - certamente na Europa ocidental - envolveu por via de regra o fortalecimento da regulação social, sujeitando as forças do mercado a regras determinadas colectivamente.

Em segundo lugar, as relações laborais implicam uma interacção entre regulação substantiva e processual. Os sistemas nacionais podem funcionar fundamentalmente através da especificação de, pelo menos, critérios básicos relativos à relação de emprego (salários mínimos, horário laboral máximo, entre outros) ou através da identificação de actores e definição de processos de interacção para a construção de regras substantivas. O primeiro modo de funcionamento pode resultar em regulação relativamente padronizada e abrangente; o segundo pode produzir resultados relativamente diferenciados e desiguais. O sistema britânico tem sido tradicionalmente marcado pela prioridade da regulação processual relativamente à substantiva (Flanders, 1970), enquanto na maior parte dos outros países europeus o equilíbrio tradicional tem sido bastante diferente.

Em terceiro lugar, podemos distinguir três modos diferentes de regulação social. Um deles baseia-se na legislação e noutros tipos de intervenção estatal, outro em acordos (ou contratos) estabelecidos através de negociação colectiva. O contraste entre regulação estatutária e 'voluntária' é bem conhecido, embora seja de alguma forma enganador. A 'negociação colectiva livre' baseia-se por via de regra em definições estatutárias de representatividade, de direitos de organização e acção colectivas e (onde tal existe) no estatuto contratual dos acordos. Por outro lado, a regulação jurídica tem geralmente pouco efeito prático, a não ser que esteja relativamente interiorizada pelos actores das relações laborais; num certo sentido, a sua aplicação é sempre negociada. Uma terceira fonte, mais difusa, de regulação social é menos frequentemente discutida: as normas, crenças e valores prevalecentes na sociedade civil - o que Regini (1995: 5) chama 'regulação comunitária'. Um exemplo seria a aceitação tradicional por uma proporção substancial de empregadores alemães da obrigação (não imposta por lei ou acordo colectivo) de admitirem novos aprendizes de forma a sustentar a reserva de competências da mão-de-obra e oferecer oportunidades de emprego de 
alta qualidade a jovens que concluem os estudos. Deve salientar-se que este complexo de normas, crenças e valores não constitui necessariamente uma ideologia consensual, como no modelo dunlopiano (1958) de um sistema de relações laborais, sendo antes usualmente um terreno de luta ideológica. O resultado desta luta normativa pode contribuir para moldar tanto a lei como a negociação colectiva.

Por consequência, um sistema de relações laborais é um campo de tensão entre, por um lado, as pressões exercidas pelo mercado no sentido da mercadorização da força de trabalho, e, por outro, as normas sociais e institucionais que asseguram a sua (relativa) 'desmercadorização' - um termo que tomo emprestado de Esping-Andersen (1990). É uma arena em que se desenrola a disputa entre a persecução de uma 'sociedade de mercado' e a defesa de princípios de 'economia moral'. A difícil conciliação destes diferentes princípios tem assumido características nacionais distintas (e frequentemente idiossincráticas), mas também um certo número de traços comuns na maior parte da Europa ocidental como resultado de compromissos de classe estabelecidos há meio século. Como Streeck apontou, a tais compromissos esteve subjacente uma evolução da relação de emprego que envolveu várias formas de uma "constelação de contrato e status" (1987: 291). Os direitos e a segurança dos empregados assentavam predominantemente em bases não-contratuais (e frequentemente prescritas por lei); os direitos dos empregadores baseavam-se no poder (social e normativamente circunscrito) considerado inerente ao contrato de trabalho. Uma característica paralela é que "o conjunto das regras implícitas ou explícitas, escritas ou não, que funcionam como contrato de trabalho em qualquer momento para qualquer empregado específico, podem ser determinadas por muitas instâncias diferentes" (Brown e Rea, 1995: 366).

$\mathrm{O}$ ajustamento destas estruturas com bases diferenciadas de direitos e obrigações de empregadores e empregados institucionalizou-se, nas várias economias europeias, de formas que se podem considerar como uma reconciliação da justiça social e da eficiência económica. Garantir o status e a segurança do empregado encorajava muitas vezes o desenvolvimento da confiança na relação de emprego e permitia orientações cooperativas dentro do processo produtivo. As perspectivas a longo prazo incorporadas no predomínio do status relativamente ao contrato - como de modo mais geral na actividade económica (por exemplo, nas relações entre as grandes empresas e os seus fornecedores de componentes ou bancos) - contrastavam com o notório 'curto prazo' anglo-americano. Os constrangimentos impostos à opção por vantagens económicas transitórias (quer fossem derivados de prescrição legal ou normas de conduta mais difusas) podem ser vistos como 
“inflexibilidades flexíveis” (Dore, 1986), que forneciam um quadro estável para efectuar mudanças consensuais nas áreas da tecnologia, métodos de produção e organização do trabalho.

Encontram-se aqui elementos centrais do que tem sido frequentemente identificado como 'capitalismo renano' ou o 'modelo social europeu' (que, segundo alguns, abrange 'Tóquio-sobre-o-Reno'): a protecção legal explícita tanto do status como do contrato; o reconhecimento de um leque mais alargado de interesses, e não apenas os dos accionistas, com legitimidade para influenciar as decisões das empresas; e, em parte como corolário, a aceitação (também frequentemente consagrada na lei) de que tais interesses só podem ser alinhados com base na representação colectiva organizada (Albert, 1993; Hutton, 1995). Na Grã-Bretanha, o pano de fundo era consideravelmente diferente em muitos aspectos, dada a tradição de 'voluntarismo' que limitou severamente a definição estatutária explícita dos direitos dos trabalhadores. No entanto, onde havia uma sólida organização colectiva e uma negociação colectiva robusta, os direitos de status que vigoravam de jure na maior parte da Europa ocidental foram alcançados de facto neste país, razão pela qual a maioria dos sindicatos se sentia satisfeita com o sistema existente.

Havia evidentemente dois principais pontos fracos inerentes a este caminho para a protecção dos trabalhadores relativamente à disciplina do mercado. Primeiro, como os Webb insistiram há mais de um século, a regulação do mercado através do poder de compensação estava condicionada pelos (des)equilíbrios flutuantes da oferta e da procura de vários tipos de capacidade produtiva (e também, obviamente, pelo grau em que o meio social e político era favorável à mobilização colectiva). Durante muitas décadas, as circunstâncias levaram os sindicalistas britânicos a acreditar complacentemente que, relativamente a estes dois aspectos, estavam em boa situação para 'jogar no mercado'. Segundo, quanto mais a lógica do mercado predomina nas relações laborais (e o 'laissez-faire colectivo' pode ser considerado como uma variante desta lógica e não como uma alternativa), tanto mais provável é que os resultados em termos de status e recompensas sejam moldados por desigualdades perante o mercado. Aqueles que já se encontram em desvantagem (devido ao seu sexo ou etnia, por exemplo) serão provavelmente mais afectados no seu acesso a organizações colectivas e quase com certeza em termos das suas relações com empregadores. Direitos colectivos mais institucionalizados e formalizados permitem contrabalançar as desigualdades sociais externas ao mercado - embora isto não aconteça automaticamente, podendo efectivamente levar ao reforço de tais desigualdades. 


\section{Novos regimes de produção: do status ao contrato?}

A existência de sistemas institucionalizados de relações laborais constitui tanto um indicador como um garante das restrições às dinâmicas puras do mercado no que respeita à relação de emprego. Nunca foi correcta a ideia de que a emergência da industrialização capitalista e a consolidação do trabalho assalariado como forma esmagadoramente predominante de trabalho produtivo envolveram uma transição simples do status para o contrato. De acordo com Streeck, existiam contratos na época pré-capitalista, enquanto "o status subsiste com vigor ainda, e especialmente, na sociedade moderna" (1992a: 43).

Contudo, será que a internacionalização económica está a levar a cabo o que épocas anteriores de desenvolvimento capitalista não conseguiram alcançar, isto é, a transição para uma sociedade de mercado e, dentro dela, a invenção genuína de um mercado de trabalho? É comum defender-se que a arquitectura do status e contrato estabelecida nos vários acordos nacionais no período do pós-guerra era adequada a um regime 'fordista' de tecnologias e mercados de produtos estáveis e previsíveis, mas que restringia uma maior flexibilidade e adaptabilidade exigida por um modelo de produção mais dinâmico e um ambiente concorrencial mais instável. Para Streeck (1987: 292-5), este último modelo envolvia pressões orientadas para dois tipos opostos de redefinição da relação de emprego: ou o reforço do status através da incorporação dos empregados na 'comunidade da empresa', como membros cujo status implicava tanto direitos como responsabilidades; ou a reafirmação do contrato através da erosão dos direitos de status, baseando, por outro lado, a autoridade empresarial no poder nu e cru de contratar e despedir. Os empregadores, acrescenta Streeck, poderiam aplicar tratamentos diferenciados aos segmentos nucleares e periféricos da sua mão-de-obra.

Muitas das experiências dos doze anos subsequentes parecem confirmar em parte esta análise, embora a corrijam em aspectos importantes. Até há pouco tempo, era plausível analisar os regimes nacionais de produção em termos de concorrência nos custos ou na qualidade. Quanto maior fosse a prioridade dada aos custos competitivos, mais os mercados de trabalho se assemelhavam a mercados. Os empregadores usavam principalmente mão-de-obra pouco qualificada, facilmente substituível e sujeita às disciplinas de trabalho tayloristas, respondendo às flutuações dos mercados de produtos com políticas de contratação e despedimento. Por contraste, a concorrência na área da qualidade implicava uma integração mais pró-activa do design do produto, da comercialização e das políticas de pessoal, com disponibilidade para investir tanto na capacidade de produção como nas qualificações dos empregados, bem como uma visão da relação de emprego 
como um compromisso recíproco de longo prazo. É óbvio que esta dicotomia estereótipada sempre foi uma simplificação redutora: cada um dos modelos de concorrência possuía contradições internas e os regimes nacionais apresentavam graus variáveis de diferenciação interna. Todavia, esta apresentação de vias alternativas para o êxito capitalista não era completamente implausível.

Mas uma das consequências da intensificação da concorrência nos mercados de produtos é que as empresas bem sucedidas têm de ser competitivas tanto a nível de custos como de qualidade. A previsão de Streeck respeitante à crescente polarização da gestão pelo contrato e pelo status parece ser contrariada em aspectos importantes pelas reacções dos principais empregadores europeus às épocas de crise. O novo regime de gestão do trabalho procura combinar o tradicional empenho no êxito empresarial dos empregados baseados no status com uma perspectiva mais dura baseada no contrato, considerando os trabalhadores como recursos descartáveis. A ambivalência deste modelo está patente no moderno conceito de 'gestão de recursos humanos', que reconhece que os empregados são seres humanos ao mesmo tempo que os desumaniza ao defini-los como recursos. Como muitos autores têm sublinhado, a gestão de recursos humanos tem um lado duro e outro suave. Este último concentra-se no desenvolvimento e progressão na carreira dos empregados, bem como no reconhecimento de que estes têm interesses investidos na comunidade da empresa; o primeiro, por outro lado, concentra-se na subordinação da gestão do trabalho à estratégia global da empresa e na redução contínua do 'número de cabeças' como índice de eficiência administrativa. Podem notar-se contradições semelhantes nas dinâmicas da organização das empresas em termos mais gerais. Por um lado, existe uma retórica vigorosa respeitante à responsabilidade social como o núcleo da identidade empresarial; por outro, há uma ênfase crescente na 'organização magra', que exporta os riscos através da subcontratação de um conjunto de actividades anteriormente realizadas a nível interno. Uma consequência importante é que muitas relações de emprego directas se tornaram indirectas, mediadas por subcontratadores cujo estatuto é também de dependência vulnerável, ou transformaram-se em 'contratos de serviços' individuais sem estatuto formal de emprego.

Isto significa que as forças do mercado estão cada vez mais a infiltrar-se na relação de emprego, mesmo nas situações em que as defesas do status eram tradicionalmente dominantes. "Os termos do qui pro quo que originalmente sustentava o estatuto do salário-emprego - isto é, a subordinação em troca de segurança - desintegraram-se" (Supiot, 1999: 336). A internacionalização do próprio capital é um dos principais impulsionadores deste 
processo. As concepções anglo-americanas do 'valor accionista' infectam cada vez mais a filosofia empresarial em países onde o modelo social europeu parecia anteriormente bem implantado. A direcção central das empresas transnacionais submete as operações locais a apertadas restrições orçamentais e estabelece níveis de 'boas práticas' nas relações de emprego de formas que reforçam a tendência para um novo contratualismo. O 'capitalismo renano’ está numa situação cada vez mais precária. Daí que se possam ver os novos regimes produtivos e concorrenciais como um estímulo à transformação do mercado laboral de ficção em realidade.

\section{A integração europeia: um projecto de contrução de mercado e um desafio aos sistemas nacionais de relações laborais}

A integração europeia pode ser vista como uma reacção a tais tendências e simultaneamente como um meio de as reforçar. O que é agora a União Europeia estabeleceu-se fundamentalmente como um mercado comum a partir do Tratado de Roma. A sua lógica central era agregar as fragmentadas economias europeias num único bloco que pudesse efectivamente contrapor-se ao desafio americano. Três décadas depois, o esforço de 'completar' este exercício através do Acto Único Europeu reflectiu uma nova dinâmica orientada para a internacionalização económica, processo a que uns chamam 'globalização' e outros 'regionalização' ou 'triadização' (constituindo a UE, a América do Norte e a Ásia-Pacífico os três principais pólos do comércio transnacional).

Os traços principais da 'globalização' são bem conhecidos. Um deles é a intensificação da concorrência entre países, à medida que novos elementos invadem os mercados de produtos anteriormente dominados por um reduzido número de economias europeias ou norte-americanas. Um segundo é a internacionalização das cadeias produtivas dentro das empresas transnacionais (ETNs) que estão desligadas dos quadros regulatórios dos sistemas nacionais de relações laborais. A mão visível das ETNs interage com a mão invisível cada vez mais coerciva do capital financeiro. As últimas três décadas testemunharam uma transformação radical: a liberalização e desregulação do capital internacional e dos mercados monetários; a aceleração das transacções (ao ponto de serem praticamente instantâneas), como resultado de desenvolvimentos nas tecnologias de informação e telecomunicações; e a derrocada do sistema de estabilização monetária internacional do pós-guerra dominado pelos Estados Unidos. O resultado é um quadro altamente volátil de fluxos de capital. As flutuações imprevisíveis (especulativas) do valor nominal das acções das empresas ou das moedas nacionais traduzem-se numa instabilidade fracturante na economia física. 
O objectivo da UE, como projecto de construção de um mercado, era o de constituir um espaço suficientemente amplo que possibilitasse que as economias de escala continuassem a ser viáveis para as empresas europeias nos mercados mundiais. Contudo, um dos corolários era o fim de muitos dos 'campeões nacionais' que tinham constituído uma base estável para as relações laborais na maior parte da Europa ocidental, uma vez que um dos objectivos do projecto do Mercado Único era a aceleração do investimento estrangeiro directo entre os países da UE e um rápido processo de consolidação de empresas através de fusões, aquisições e empreendimentos conjuntos.

Em décadas anteriores, o 'problema das multinacionais' para os sindicatos europeus era relativamente estreito e específico: como conter as ETNs estrangeiras (principalmente americanas) dentro dos estruturas reguladoras dos sistemas europeus de relações laborais. Na década de 1990, o problema tornou-se mais amplo e mais grave: a internacionalização de segmentos significativos do 'capital nacional' e o abandono potencial por parte de empresas chave do seu papel tradicional dentro dos sistemas nacionais de 'parceria social'. Talvez o caso mais dramático seja o da Suécia, onde os principais empregadores se 'integraram' na UE muito antes da entrada formal do país na união e demoliram o clássico 'modelo sueco' centralizado de relações laborais de forma a poderem mais facilmente seguir políticas de emprego mais específicas para cada empresa e mais internacionalizadas. $\mathrm{Na}$ maioria dos outros países europeus evidenciam-se pressões análogas.

A importância crescente da 'euro-empresa' (Marginson e Sisson, 1994) ameaça formas estabelecidas de padronização nacional entre empresas, cujo principal instrumento tem sido o acordo colectivo sectorial. Daí advém o receio do 'dumping social', isto é, que muitas empresas desloquem a produção dos países com salários altos e critérios laborais rigorosos para aqueles em que os custos e as regulamentações laborais são mais baixos. Quer o 'dumping social' seja ou não uma realidade grave, há certamente evidências de que muitas ETNs usam a ameaça da relocalização como factor disciplinador nas negociações colectivas. Um desafio diferente deriva do facto de que, ao mesmo tempo que as ETNs tipicamente atribuem uma significativa autonomia operacional às unidades locais, elas estabelecem normalmente um regime interno competitivo, procurando difundir sistemas de 'boas práticas' em todas as suas filiais (Ferner, 1998). Isto tem reforçado a viragem para formas mais 'flexíveis' de organização do trabalho, horário laboral, distribuição de tarefas e sistema remuneratório, todos eles elementos centrais nas regras padronizadas, definidas pela lei nacional e pela negociação colectiva, reforçando a mudança do status para o contrato. 
Quanto à nova força coerciva dos mercados globais de capitais, foi em parte como resposta à sua volatilidade que a UE adoptou o projecto da União Económica Monetária. A solução hobbesiana para a nova anarquia da finança internacional era nomear um soberano: o Banco Central Europeu (em grande medida uma cópia maior do Bundesbank), com poderes disciplinares reforçados pelos 'critérios de convergência' de Maastricht. Isto exige um alinhamento coercivo dos regimes fiscais e monetários, encarnando princípios que são extremamente deflacionários nas suas implicações. Para cumprir os requisitos da união monetária, os governos em toda a Europa têm sido incitados a impor novos freios ao emprego público e restrições ao 'salário social'. A consequência tem sido uma pressão crescente sobre os princípios da 'parceria social' que caracterizam a maior parte dos sistemas europeus de relações laborais.

Um modo de conceptualizar os desenvolvimentos dos últimos anos é vê-los como uma forma de 'desnacionalização' das relações laborais. $\mathrm{Na}$ maioria dos países, estas surgiram inicialmente a partir de uma base local ou sectorial (reflectindo os contornos dos mercados de trabalho), mas no século XX consolidaram-se numa estrutura institucional nacional. A inserção nacional dos sistemas de relações laborais constituiu por longo tempo - pelo menos em muitos casos - uma fonte de resistência e força, mas pode cada vez mais ser encarada como uma fragilidade. Tal como entendemos o termo hoje em dia, as relações laborais foram uma invenção da era do preeminente Estado-nação. Na maior parte dos países da Europa Ocidental, os sistemas 'modernos' de relações laborais consolidaram-se num contexto de relativa segurança de emprego (pelo menos para um núcleo substancial de trabalhadores fabris, principalmente homens, em grandes empresas) sob condições económicas de 'pleno' emprego, frequentemente apoiadas em suportes jurídicos. Por sua vez, isto era viabilizado por uma procura estável e crescente nos principais mercados de produtos e por restrições institucionais e de outra ordem sobre a concorrência destrutiva do mercado. O capitalismo organizado que alcançou o seu cume nos anos 50 e 60 do século Xx ajudou a instituir os sindicatos como actores centrais numa variedade de sistemas nacionais de regulação do emprego. A relativa autonomia da organização política e da economia de cada país constituía o contexto dos diferentes sistemas nacionais de regulação do emprego.

As instituições fundadas no período de formação da industrialização europeia, bem como os vários sistemas de gestão macroeconómica de influência keynesiana no período do pós-guerra, dependiam da capacidade regulatória do Estado-nação. É realmente um facto que na maior parte das 
economias europeias a importância fundamental do sector da exportação assegurava a compatibilidade das políticas de relações laborais com a competitividade internacional. Todavia, os Estados nacionais e os parceiros da negociação colectiva podiam tratar o mercado de trabalho como um sistema mais ou menos fechado. Existia diversidade de sistemas de relações laborais precisamente porque tais sistemas envolviam relações nacionais entre actores nacionais.

A consequência da integração económica transnacional é que as dinâmicas dos mercados estão cada vez mais sujeitas a determinação externa. A intensificação da competitividade internacional nos mercados de produtos, a imposição externa de constrangimentos às políticas dos governos, assim como as decisões de localização das ETNs, impõem novos, onerosos e frequentemente imprevisíveis constrangimentos à agenda das relações laborais nacionais.

É evidente que os três elementos de regulação social anteriormente identificados como a base dos sistemas de relações laborais são todos afectados por estas tendências. A regulação através da negociação colectiva perde eficácia - mesmo nos casos em que continua formalmente em vigor para a maioria dos empregados, como acontece na maior parte da Europa Ocidental, embora já não na Grã-Bretanha - perante as comparações coercivas inerentes à internacionalização económica. Uma das características tem sido a pressão relativa à adopção de normas colectivas cada vez mais flexíveis, permitindo uma maior liberdade de acção a nível empresarial. Outra característica é que, quer a negociação ocorra primordialmente a nível de empresa, quer a nível sectorial ou macroeconómico, parece cada vez mais patentear aspectos de negociação de concessões.

A vontade ou capacidade dos governos nacionais de impor uma regulamentação do emprego também se encontra debilitada. O entusiasmo político manifestado na maior parte dos países europeus - e também a nível da UE - pela 'flexibilidade' e 'desregulação' como a melhor receita para a competitividade reforçou e ajudou a legitimar o avanço do contrato e a erosão do status no emprego. Os governos britânicos foram evidentemente os que comandaram esta ofensiva, e as eleições de 1997 apenas trouxeram mudanças limitadas neste aspecto: ao apresentar o programa trabalhista respeitante à legislação das relações laborais, Blair declarou orgulhosamente (para alguns afrontosamente) que, "mesmo depois das mudanças que propomos, a Grã-Bretanha terá o mercado de trabalho menos regulado de todas as principais economias do mundo" (1998: 3). Contudo, a doença britânica parece ser contagiosa e o processo tem aumentado a capacidade das ETNs de estabelecer regimes específicos por empresa, dimi- 
nuindo e potencialmente debilitando a capacidade reguladora dos sistemas nacionais de relações laborais. A 'desregulação' também consolidou o domínio dos bancos centrais e de outras instituições financeiras, impondo disciplinas que são inerentemente antagónicas aos princípios da protecção e parceria social que subjazem à maior parte dos sistemas europeus de relações laborais.

Por sua vez, estes desenvolvimentos erodem a força das normas e valores mais intangíveis que têm sustentado o modelo social europeu e constituído as bases do status do empregado. Os produtos de milhares de fábricas de mestres em administração de empresas (MBA), que cada vez mais conduzem as decisões das empresas e colonizam os corredores do poder político, não perdem tempo com tais sentimentalismos. De facto, uma das consequências, talvez intencional, da circulação transnacional de gestores de topo das ETNs é o seu isolamento relativamente aos códigos de conduta específicos de cada país, que anteriormente estavam na base dos diferentes sistemas empresariais. Estes decisores encontram-se, assim, desligados das redes nacionais de solidariedade colectiva dos empregadores e das normas da economia moral que têm, em geral, sustentado a eficácia reguladora dos sistemas nacionais de relações laborais; as suas decisões, regidas pelo mercado, encontram-se cada vez mais 'desenraizadas'.

Seria perigoso e errado adoptar uma interpretação demasiadamente económico-determinista das tendências actuais, as quais contêm ambiguidades e contradições. A intensificação transnacional das forças do mercado tem implicações reais e importantes que constituem um desafio à capacidade reguladora dos regimes de relações laborais a nível nacional, mas a utilização ideológica das ideias da desregulação (assim como, em termos mais gerais, da globalização) ajuda a criar uma presunção fatalista de que 'não há alternativas'. Descobrir alternativas é, pelo contrário, a tarefa que compete à análise das relações laborais.

\section{O desafio para o trabalho: a reinvenção transnacional das relações laborais}

Poderá reconstituir-se uma efectiva regulação social do emprego, sob ameaça a nível nacional, no plano supranacional? Será ao nível europeu que o trabalho, através da sua "rede espessa de actividades sindicais transnacionais" (Martin e Ross, 1999: 313), pode responder com êxito ao desafio colocado pelo facto de "o reforço do status uniforme de emprego ser exigido precisamente pela diferenciação dos contratos de trabalho" (Grahl e Teague, 1994: 387)? Será que as relações laborais europeias estão já realmente a tomar forma? 
O debate sobre a possibilidade de um regime efectivo de relações laborais a nível da UE (a 'Europa social') dura há uma década ou mais e tem gerado uma polarização de pontos de vista. Uma das abordagens, muitas vezes explicitamente ligada a teorias de 'alastramento' da consolidação da organização política europeia, faz uma avaliação optimista da UE como veículo de regulação social do mercado de trabalho em curso de internacionalização (Falkner, 1998). Em termos dunlopianos, a existência de 'actores' a nível europeu cujas interacções resultam na produção de regras (o 'acordo dos parceiros sociais' de 1991, as directivas sobre o emprego adoptadas ao abrigo dos procedimentos de Maastricht para a 'legislação negociada' ou a criação de Conselhos de Empresa Europeus como novas instituições supranacionais com potencial regulatório) fornece provas do nascimento de um sistema europeu de relações laborais (Jensen et al., 1999; Lecher e Rüb, 1999). A 'subsidiaridade' pode ter obstruído o processo de uma regulação abrangente sobre o emprego, mas também estimulou o desenvolvimento de uma dimensão regional forte dentro da UE, criando novo espaço para a intervenção do movimento operário. Para além disto, os vários programas abrangidos pelos fundos estruturais da UE têm um importante papel redistributivo, contrariando em certa medida a lógica puramente mercantil da integração. Mais recentemente, a persecução de uma estratégia de emprego resultou em decisões que podem ser descartadas como meramente simbólicas, mas também aplaudidas como os alicerces de um novo regime europeu contra-deflacionário; ao mesmo tempo, a introdução da moeda única criou novas pressões para a coordenação transnacional das negociações colectivas (Goetschy, 1994, 1999; Jacobi, 1996; Marginson e Sisson, 1998).

Uma outra avaliação alternativa é bem mais pessimista: a UE surgiu a partir de um processo de 'integração negativa' com o objectivo prioritário de facilitar as relações de mercado a nível pan-europeu, sendo que um regime económico liberal oferece o terreno em que o capital transnacional pode dividir e reinar. $\mathrm{O}$ investimento é canalizado para os regimes nacionais de mercado de trabalho que oferecem as melhores perspectivas para a acumulação, encorajando a debilitação competitiva da negociação colectiva e dos Estados-Providência a nível nacional. Uma estrutura efectiva de regulação do emprego a nível da UE poderia limitar tais pressões, mas parece haver poucas probabilidades de se efectivar precisamente porque alguns governos nacionais vêem vantagens na concorrência entre regimes. Há, portanto, uma coligação poderosa, embora geralmente tácita, entre alguns (muitos?) governos nacionais e agentes-chave do capital. Os próprios trabalhadores europeus estão divididos, e mesmo que estivessem unidos seriam a parte mais fraca, lutando contra a tendência instalada do liberalismo de mercado 
que sustenta a integração europeia. A 'Europa social' é uma questão de forma e não de substância (Streeck, 1992b, 1994, 1995, 1997, 1998; Streeck e Schmitter, 1991; Visser, 1998).

Há ainda outros que procuram uma terceira via, propondo uma perspectiva 'euro-realista' que reconhece a modéstia das conquistas respeitantes à regulação social europeia sem, no entanto, as menosprezar (Buda, 1998; Ross, 1994). Há espaço para mais avanços, em parte porque as provas da tese do 'dumping social' não são convincentes; os custos laborais não parecem ser o principal determinante das decisões das ETNs relativamente à localização das suas operações. Se a concorrência entre regimes continuar a ter limites, pode haver espaço para sustentar estruturas reguladoras a nível nacional e ao mesmo tempo construir uma arquitectura de regulação transnacional.

Não pretendo recapitular aqui estas controvérsias em pormenor, pois isto exigiria muito mais espaço do que aquele de que disponho e, de qualquer das formas, o meu foco é outro. Uma parte da dificuldade reside nas contradições da formação institucional que é a UE: "um sistema de governação singular e singularmente complexo" (Streeck e Schmitter, 1991: 151). É composto por um Parlamento que não é uma legislatura, uma Comissão que é 'empresário de políticas' (Majone, 1998: 24) e portador intermitente de um projecto federalista cujo objectivo é viabilizar um sistema europeu de relações laborais relevante, bem como por um Conselho que, em circunstâncias normais, se empenha firmemente na tarefa de refrear tais ambições. O resultado é uma 'charada regulatória' (Rhodes, 1995) dentro de um conjunto de processos que "pairam indecisos entre a política e a diplomacia, entre estados e mercados e entre governos e governação" (Laffan, 1998: 236). Poderá haver espaço para um reforço cumulativo e iterativo da extensão e profundidade da dimensão social - ou não.

Coloca-se, contudo, à análise das relações laborais uma importante questão que raramente é enfrentada de modo explícito: podemos encarar a regulação supranacional como uma cópia ampliada das relações laborais nacionais? É isto que parece estar subentendido se aplicarmos simplesmente o modelo de Dunlop ao palco europeu e também talvez esteja implícito em muitos casos em que se usa a noção de 'governação de múltiplos níveis' (Eberwein et al., 2000: 203; Falkner, 1998) como mecanismo analítico. Mas como é que esses níveis se comunicam entre si? "As instituições de relações laborais emergentes a nível europeu não estão prestes a transformar-se numa réplica de um sistema nacional de relações laborais a uma escala maior" (Streeck, 1998: 435). Há poucas perspectivas de que se criem cópias directas a nível transnacional da negociação colectiva e do 'jogo político’ do plano 
nacional, uma vez que - como tem sido repetidamente defendido - a UE não é em aspectos fundamentais um Estado supranacional e os 'parceiros sociais' europeus não são sindicatos ou organizações de empregadores nacionais com autoridade a nível superior.

O risco reside no investimento de demasiada energia e recursos na busca de uma forma elaborada de substância mínima. É este o caso do complexo ritual do 'diálogo social', um processo moroso que tem poucas semelhanças com a verdadeira negociação colectiva. Da mesma forma, os esforços para estabelecer regulamentação através de directivas da UE (ou conseguir acordos bipartidos à 'sombra da lei') têm alcançado resultados que mesmo os entusiastas admitem ser relativamente limitados em termos do seu impacto na maioria dos países da UE (o Reino Unido é talvez a excepção permanente), embora haja esperança de que possam constituir as bases de futuros avanços.

Uma consideração fundamental é que a integração europeia requer uma nova invenção estratégica. Segundo Piven e Cloward (2000: 414), a internacionalização económica debilita muitos dos tradicionais pontos fortes dos movimentos operários, mas "continuam a persistir (...) possibilidades subjacentes de poder". No entanto, os sindicatos frequentemente manifestam inércia organizativa e permanecem aprisionados por orientações estratégicas que anteriormente foram eficazes, mas que perderam força perante os novos desafios. Assim, os potenciais recursos de poder dos movimentos operários - a oportunidade de se concentrarem nos pontos fracos do capital transnacional - não se reflectem no seu repertório de estratégias efectivas.

Um desses pontos fracos é ideológico. Apesar do grau em que os 'mercados livres' se tornaram parte da normalidade política das duas últimas décadas, o impacto destrutivo do liberalismo económico nas vidas das pessoas vulgares é muitas vezes amargamente ressentido. Não poderiam os sindicatos europeus mobilizar esse descontentamento? Esta questão estabelece a ponte com a anterior discussão sobre a economia moral. Uma falha que subjaz à procura de uma regulamentação a nível europeu, quer através de mecanismos supranacionais equivalentes da negociação colectiva, quer através de acção legislativa, é que tais processos, bem como os instrumentos daí derivados, não têm o apoio das perspectivas partilhadas e dos compromissos normativos mais difusos que lhes conferem em grande medida efectividade a nível nacional. A busca de um sistema europeu de relações laborais tem sido principalmente um projecto de elite, conduzido por burocratas. Se não responder aos anseios e aspirações populares, todo o elaborado repertório de comunicados, opiniões conjuntas, projectos e revisões de 
projectos de directivas, bem como tudo o resto que vem da Comissão, mais não é do que um entretenimento sem relevância para o mundo real do trabalho e do emprego. O que falta é uma economia moral a nível europeu - para além do tradicional empenhamento abstracto numa 'economia de mercado social' por parte dos social-democratas e dos democratas cristãos, um empenhamento que sempre foi ambíguo e que foi sendo progressivamente minado pelas pressões mercantilizantes do final do século XX.

O objectivo de uma regulação europeia efectiva - a reconstrução do estatuto do empregado a nível supranacional - continuará a ser uma quimera a não ser que se consiga mobilizar o apoio popular. No entanto, tem que se contar com a existência de uma 'opinião pública' dominante na maioria dos países europeus que manifesta desconfiança, se não mesmo um absoluto antagonismo, relativamente à ideia da integração europeia. "A hostilidade difundida entre os cidadãos relativamente ao processo de unificação é reforçada pelo discurso da maioria dos dirigentes políticos, que apresentam a União Europeia como a adaptação necessária à globalização, com o corolário do ajustamento económico, da flexibilidade dos mercados de trabalho e encolhimento do Estado Providência" (Castells, 1998: 326). Mais vezes do que seria desejável, os representantes dos trabalhadores europeus têm abraçado de forma demasiado acrítica o processo de unificação como uma mercantilização, alimentando inconscientemente o desencanto relativamente ao seu próprio estatuto de representantes.

Isto poderia ser revertido se fosse possível formular e difundir critérios claros de economia moral que encontrassem eco em todos os países e línguas, inspirando entusiasmo em vez de alienação. Como se poderá construir uma economia moral europeia significativa? As ideias, os ideais e as identidades emergem geralmente através da contestação e luta; às vezes representam uma conciliação de interesses conflituais, mas também constituem frequentemente pontos de referência a partir dos quais as maiorias oprimidas podem desafiar as minorias imperiosas. São tanto o produto como a base da sociedade civil, que eu entendo como uma esfera de relações sociais distinta quer do poder do Estado, quer do domínio do mercado. No plano nacional, os sindicatos de muitos países devem desde há muito a sua influência em grande medida ao seu estatuto de actores fundamentais na sociedade civil; mais recentemente, reconheceram que só podem suster ou reconsquistar um papel significativo através do estabelecimento de laços efectivos com outros elementos da sociedade civil. Por contraste, a debilidade de uma sociedade civil europeia constitui um dos maiores obstáculos à criação de um verdadeiro sistema europeu de relações laborais. 
Conceptualmente, já existe uma sociedade civil europeia. A Comissão Europeia declarou desejar promover um 'diálogo civil' a nível europeu e dá apoio material a uma grande variedade de organizações não-governamentais que podem funcionar como interlocutores (assim como subsidia a representação de empregados dentro das rotinas de diálogo social há mais tempo estabelecidas). Mas isto é só fachada. As organizações autorizadas por instâncias superiores não podem por via disso ser realisticamente vistas como representantes da vontade popular. Se não houver uma consciência difundida da cidadania europeia é fátuo falar de uma sociedade civil europeia.

Contudo, não estão totalmente ausentes indícios reais da existência de uma sociedade civil europeia. Um exemplo óbvio é a luta pelos direitos das mulheres, que, a partir dos anos sessenta, gerou um clima de opinião que constituiu a base das decisões inovadoras do Tribunal Europeu e das políticas intervencionistas da Comissão no campo da igualdade de oportunidades. Um outro exemplo foi a ira causada pelo encerramento da fábrica de Vilvoorde pela Renault, que reforçou as reivindicações de políticas europeias de emprego efectivas e criou um potencial para o fortalecimento da directiva dos Conselhos de Empresa Europeus. Em certa medida, a ameaça da BMW de encerrar a produção nas fábricas britânicas da Rover provocou reacções semelhantes. $\mathrm{Na}$ altura em que escrevo este artigo, a resistência à decisão da GM de fechar a fábrica da Vauxhall em Luton - provocando uma greve simbólica de 40000 trabalhadores em toda a Europa - reflecte uma afirmação semelhante dos direitos morais e de status dos trabalhadores perante o estreito contratualismo do capital multinacional.

A consolidação da sociedade civil europeia emergente deve ser considerada como uma importante tarefa para os sindicatos e outros apoiantes de uma efectiva regulação social do emprego. Um dos problemas é que o próprio conceito de sociedade civil tem sido apropriado e desvalorizado pelos defensores de uma 'terceira via' profundamente ambígua, muitas vezes para humanizar as políticas neoliberais. Como Beck afirmou, seria mais apropriado usarmos o conceito de uma "sociedade de cidadãos que lutam a favor dos direitos das pessoas" (uma tradução aproximada de zivilcouragierte Gesellschaft) (2000: 11). Ou, nas palavras de Standing, "é necessária uma rede de associações de cidadãos para dar voz a todos os que enfrentam a insegurança" (1999: 387).

Para os sindicatos virem a reafirmar a sua relevância como representantes do mundo do trabalho e como actores a nível europeu, tem de haver uma mudança radical na importância atribuída ao próprio trabalho. Ao mesmo tempo que se envolvem no processo de integração europeia, têm de 
se tornar muito mais categóricos e vigorosos na sua oposição ao avanço desumanizante das forças de mercado. Por contraste com o diálogo social tal como é actualmente entendido, é necessário que haja um diálogo social interno para acordar em perspectivas comuns para o trabalho à escala europeia, para construir alianças com as ONGs apropriadas e para criar recursos e mesmo armas para fazer com que as suas opiniões sejam efectivamente ouvidas. As expressões mais dramáticas da economia moral nos últimos anos - como em Seattle, Nice ou Davos - têm sido essencialmente negativas e opositivas. Em última análise, a rejeição das prioridades determinadas pelo mercado só pode ter êxito se se voltar para o futuro em vez de para o passado e se for enquadrada por uma agenda positiva de direitos humanos. Com tais fundamentos, poderá tornar-se possível talhar processos de 'regulação comunitária' a nível supranacional, bem como estimular a pressão das bases, a qual pode reforçar a busca de outros modos de regulação europeia. Será uma luta difícil, cujo objectivo deve ser o de construir uma nova forma de inserção dos processos do mercado a nível europeu e, portanto, uma nova defesa do status dos empregados - particularmente dos que se encontram em posições mais vulneráveis dentro do mercado de trabalho 'real' que está a surgir. Os académicos que partilham estas preocupações têm o dever de ajudar nesta luta, que deveria estar no centro de um conflito de perspectivas sobre o significado e o futuro da Europa.

Até agora, os estudiosos limitaram-se a interpretar o mundo das relações laborais de diferentes maneiras, mas a questão é reinventá-lo.

Tradução de

João Paulo Moreira

\section{Referências Bibliográficas}

Albert, M. (1993), Capitalism against Capitalism. London: Whurr.

Beck, U. (2000), "Mehr Zivilcourage bitte”, Die Welt (25 Maio), 11.

Blair, T. (1998), "Foreword", Fair Deal at Work. London: HMSO, Cm 3968, 3-4.

Boyer, R. (1996), "State and Market: A New Engagement for the Twenty-First Century?", in R. Boyer; D. Drache (orgs.), States Against Markets: The Limits of Globalization. London: Routledge, 84-114.

Brown, W.; Rea, D. (1995), “The Changing Nature of the Employment Contract”, Scottish Journal of Political Economy, 42(3), 363-377.

Buda, D. (1998), “On Course for European Labour Relations?”, in W. Lecher; H.-W. Platzer (orgs.), European Union-European Industrial Relations. London: Routledge, 21-44. 
Castells, M. (1998), End of Millennium. Oxford: Blackwell.

Commons, J. R. (1909/1968), “American Shoemakers, 1648-1895”, Quarterly Journal of Economics, 24, reeditado em R. L. Rowan; H. R. Northrup (orgs.), Readings in Labor Economics and Labor Relations. Homewood: Irwin, 60-76.

Commons, J. R. (1924), Legal Foundations of Capitalism. New York: Macmillan.

Crouch, C.; Streeck, W. (orgs.) (1997), Political Economy of Modern Capitalism. London: Sage.

Dore, R. (1986), Flexible Rigidities. London: Athlone.

Durkheim, E. (1933), The Division of Labor in Society. New York: Macmillan.

Eberwein, W.; Tholen, J.; Schuster, J. (2000), Die Europäisierung der Arbeitsbeziebungen als politisch-sozialer Prozeß. Munich: Hampp.

Erbès-Seguin, S. (1999), "Le contrat du travail: Une relation hybride", in S. Erbès-Seguin (org.), Le contrat: Usages et abus d'une notion. Paris: Desclée de Brouwer, 217-231.

Esping-Andersen, G. (1990), The Three Worlds of Welfare Capitalism. Cambridge: Polity. Falkner, G. (1998), EU Social Policy in the 1990s: Towards a Corporatist Policy Community. London: Routledge.

Ferner, A. (1998), "Multinationals, 'Relocation' and Employment in Europe”, in J. Gual (org.), Job Creation: The Role of Labour Market Institutions. Cheltenham: Edward Elgar, 165-196.

Flanders, A. (1970), Management and Unions. London: Faber.

Friot, B. (1999), "Les enjeux actuels d'une définition contractuelle de l'emploi", in S. Erbès-Seguin (org.), Le contrat: Usages et abus d'une notion. Paris: Desclée de Brouwer, 195-215.

Goetschy, J. (1994), “A Further Comment on Wolfgang Streeck's 'European Social Policy after Maastricht'", Economic and Industrial Democracy, 15, 477-485.

Goetschy, J. (1999), “The European Employment Strategy: Genesis and Development”, European Journal of Industrial Relations, 5(2), 117-137.

Grahl, J.; Teague, P. (1994), "Economic Citizenship in the New Europe”, Political Quarterly, 65(4), 379-396.

Granovetter, M. (1985), "Economic Action and Social Structure: The Problem of Embeddedness”, American Journal of Sociology, 91, 481-510.

Gray, J. (1998), False Dawn: The Delusions of Global Capitalism. London: Granta.

Hutton, W. (1995), The State We're in. London: Cape.

Jacobi, O. (1996), “European Monetary Union: A Quantum Leap”, Transfer, 2(2), 233-244.

Jensen, C. S.; Madsen, J. S.; Due, J. (1999), "Phases and Dynamics in the Development of EU Industrial Relations”, Industrial Relations Journal, 30(2), 118-134.

Laffan, B. (1998), “The European Union: A Distinctive Model of Internationalization”, Journal of European Public Policy, 5(2), 235-253. 
Lecher, W.; Rüb, S. (1999), “The Constitution of European Works Councils”, European Journal Industrial Relations, 5(1), 7-25.

Majone, G. (1998), "Understanding Regulatory Growth in the European Community”, in D. Hine; H. Kassim (orgs.), Beyond the Market: The EU and National Social Policy. London: Routledge, 14-35.

Marginson, P.; Sisson, K. (1994), “The Structure of Transnational Capital in Europe”, in R. Hyman; A. Ferner (orgs.), New Frontiers in European Industrial Relations. Oxford: Blackwell, 15-51.

Marginson, P.; Sisson, K. (1998), “European Collective Bargaining: A Virtual Prospect?”, Journal of Common Market Studies, 36(4), 505-528.

Martin, A.; Ross, G. (1999), "In the Line of Fire: The Europeanization of Labor Representation”, in A. Martin; G. Ross (orgs.), The Brave New World of European Labor. New York: Berghahn, 312-367.

Mitchell, A. (1998), "Industrial Democracy: Reconciling Theories of the Firm and State", International Journal of Comparative Labour Law and Industrial Relations, 14(1), 3-40.

Marsden, D. (1999), A Theory of Employment Systems. Oxford: Oxford UP.

Piven, F. F.; Cloward, R. A. (2000), "Power Repertoires and Globalization", Politics ESociety, 28(3), 413-430.

Polanyi, K. (1957), The Great Transformation. Boston: Beacon.

Regini, M. (1995), Uncertain Boundaries. Cambridge: Cambridge UP.

Regini, M. (2000), “The Dilemmas of Labour Market Regulation”, in G. Esping-Andersen; M. Regini (orgs.), Why Deregulate Labour Markets? Oxford: Oxford UP, 11-29.

Rhodes, M. (1995), "A Regulatory Conundrum: Industrial Relations and the Social Dimension”, in S. Leibfried; P. Pierson (orgs.), European Social Policy: Between Fragmentation and Integration. Washington: Brookings, 78-122.

Ross, G. (1994), "On Half-Full Glasses, Europe and the Left”, Economic and Industrial Democracy, 15, 486-496.

Sayer, A. (1995), Radical Political Economy: A Critique. Oxford: Blackwell.

Standing, G. (1997), "Globalization, Labour Flexibility and Insecurity: The Era of Market Regulation”, European Journal of Industrial Relations, 3(1), 7-37.

Standing, G. (1999), Global Labour Flexibility: Seeking Distributive Justice. London: Macmillan.

Streeck, W. (1987), “The Uncertainties of Management in the Management of Uncertainty", Work, Employment and Society, 1(3), 281-308.

Streeck, W. (1992a), Social Institutions and Economic Performance. London: Sage.

Streeck, W. (1992b), "National Diversity, Regime Competition and Institutional Deadlock", Journal of Public Policy, 12(4), 301-330.

Streeck, W. (1994), "European Social Policy after Maastricht", Economic and Industrial Democracy, 15, 151-77. 
Streeck, W. (1995), “From Market Making to State Building?”, in S. Leibfried; P. Pierson (orgs.), European Social Policy: Between Fragmentation and Integration. Washington: Brookings, 389-431.

Streeck, W. (1997), "Neither European nor Works Councils”, Economic and Industrial Democracy, 18(2), 325-337.

Streeck, W. (1998), “The Internationalization of Industrial Relations in Europe”, Politics ESociety, 26(4), 429-459.

Streeck, W.; Schmitter, P. C. (1991), "From National Corporatism to Transnational Pluralism”, Politics E Society, 19(2), 133-164.

Supiot, A. (1999), "The Transformation of Work and the Future of Labour Law in Europe”, International Labour Review, 138(1), 31-46.

Thompson, E. P. (1971), "The Moral Economy of the English Crowd in the Eighteenth Century", Past and Present, 50, 76-136.

Visser, J. (1998), “Learning to Play: The Europeanisation of Trade Unions”, in P. Pasture; J. Verberckmoes (orgs.), Working-Class Internationalism and the Appeal of National Identity. Oxford: Berg, 231-257. 